\title{
Ionospheric plasma density structures associated with magnetopause motion: a case study using the Cluster spacecraft and the EISCAT Svalbard Radar
}

\author{
F. Pitout ${ }^{1}$, C. P. Escoubet ${ }^{1}$, and E. A. Lucek $^{2}$ \\ ${ }^{1}$ European Space Agency, Research and Scientific Support Department, Solar and Solar-Terrestrial Missions Division, \\ Keplerlaan 1, 2201 AZ Noordwijk, The Netherlands \\ ${ }^{2}$ Imperial College, Space and Atmospheric Physics Group, Prince Consort Road, London, SW7 2BZ, UK
}

Received: 15 October 2003 - Revised: 29 March 2004 - Accepted: 16 April 2004 - Published: 14 July 2004

Part of Special Issue "Spatio-temporal analysis and multipoint measurements in space"

\begin{abstract}
On 5 January 2003, the footprint of the Cluster spacecraft, then orbiting in the dayside magnetosphere near the magnetopause, was in the close vicinity of the EISCAT Svalbard Radar (ESR) in the dayside afternoon sector. This configuration made possible the study of the magnetopause motion and its direct consequences on the ionospheric plasma at high latitude. Cluster observed multiple magnetopause crossings despite its high latitude, while on the ground the magnetic activity was very low, whereas the ionospheric plasma sounded by the ESR exhibited poleward moving plasma density structures. In this paper, we compare the satellite and radar data, in order to show that the plasma density structures are directly related to the magnetopause motion and its associated pulsed ionospheric flow. We propose that the variations in electric field make the convection velocity vary enough to alter the electron population by accelerating the chemistry in the F-region and act as a source of electron depletion. The magnetopause motion is in this case, a source of plasma density structures in the polar dayside ionosphere.
\end{abstract}

Key words. Magnetospheric physics (magnetopause, cusp, arid boundary layers, magnetosphere-ionosphere interactions) - Ionosphere (ionospheric disturbances)

\section{Introduction}

\subsection{Polar patches}

Polar patches in the high-latitude dayside ionosphere are commonly defined as regions of enhanced electron density compared to the "background" density. Yet interestingly enough, they are most of the time produced by depletion of the electron population concentration in their surroundings.

Correspondence to: F. Pitout

(fpitout@ rssd.esa.int)
Let us summarize quickly the main mechanisms that have been proposed so far to explain their formation.

Pulsed reconnection is one of the main sources of polar patches. This process may act in two different ways. To understand these, we need to describe a little bit the consequences of pulsed reconnection on the dayside polar ionosphere and in the ionospheric cusp. After reconnection between interplanetary magnetic field lines and magnetospheric field lines, newly-reconnected open field lines will move quickly eastward or westward (depending on IMF $B_{y}$ ) under the magnetic tension force, and then tend to move antisunward, dragged by the solar wind. At the ionospheric footprint of these field lines, there are therefore two main processes acting against each other. On the one hand, magnetosheath electron precipitation leads to a slow builtup of the electron density in the ionosphere (Whitteker, 1977). On the other hand, the same reconnected flux tube undergoes fast convection that favors ion frictional heating and thus, electron depletion (Schunk et al., 1975). The combined effect of the electron precipitation and convection has been studied by Pitout and Blelly (2003) and was shown to depend on the origin of the flux tube and on the electric field amplitude. In fact, pulsed reconnection may yield polar patches by either increasing or decreasing the electron density in the ionospheric F-region.

Pulsed reconnection has also an indirect effect that is also thought to produce polar patches. Each burst of dayside reconnection would be able to chop the solar insolated tongue of ionization and allow some high-density cold plasma to get into and drift across the polar cap (Lockwood and Carlsson, 1992).

A similar idea was proposed by Rodger et al. (1994). According to these authors, zonal flow changes in the ionospheric convection due to variations in the y-component of the IMF could also lead to polar patch formation by bringing high-density plasma from the afternoon sunlit ionosphere for intervals when IMF $B_{y}$ is positive. 

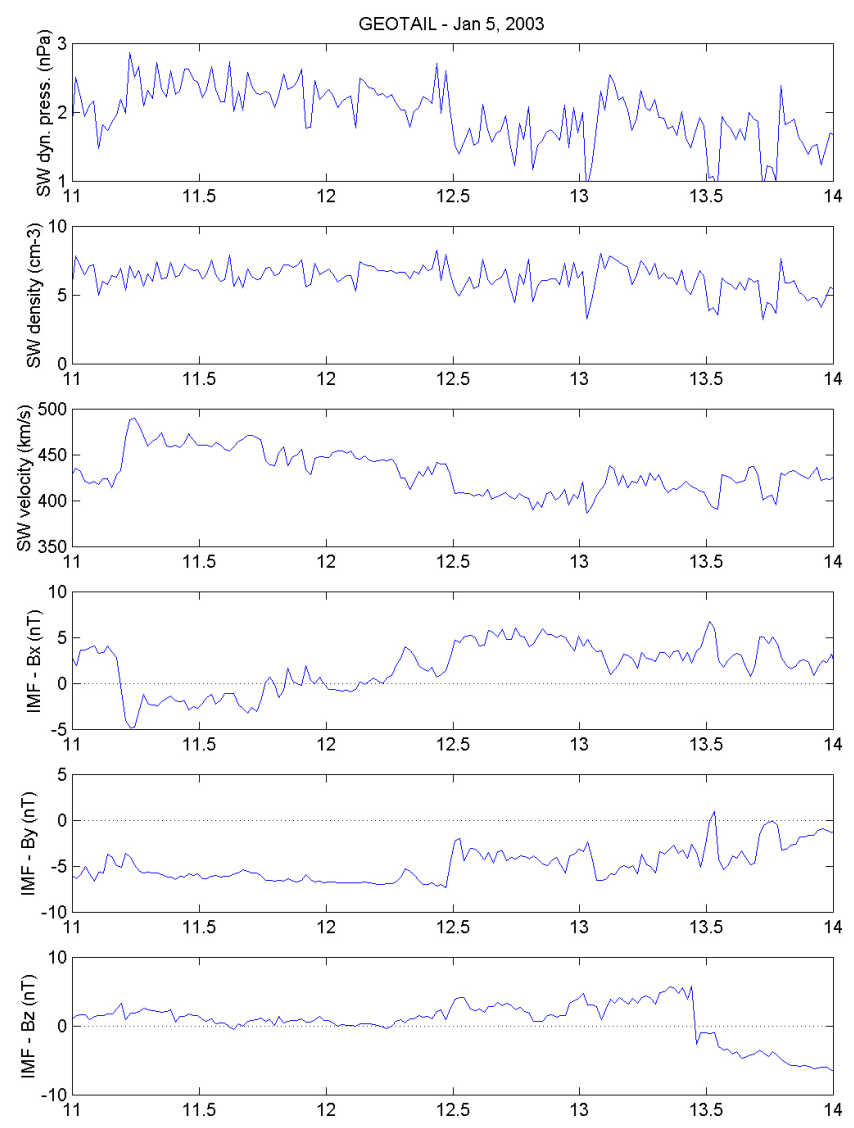

Fig. 1. Geotail data from CPI and MGF with, from top to bottom, the solar wind dynamic pressure, the solar wind density, the solar wind bulk velocity, and the three components of the interplanetary magnetic field in the GSE coordinate system.

Another explanation recently proposed is the influence of traveling convection vortices (TCV) on the ionosphere. The region between two vortices, where the plasma flow is fast, favors ion frictional heating and consequently, would act as a source of electron depletion (Valladares et al., 1999).

All in all, it appears that periodic or pseudo-periodic variations of precipitation and/or convection electric field may potentially lead to the formation of density structures in the polar ionosphere. Besides, one of the common characteristics of polar patches (see a summary of characteristics by Rodger et al., 1994) is that they are observed when the IMF is southward ( $B_{z}$ negative). We report in this paper observation of polar patches under slightly northward and strongly dawnward IMF. These features lead us to consider another possibility: the patch formation by ULF waves.

\subsection{ULF waves}

The ionospheric response to ultra low-frequency (ULF) waves is obvious in ground magnetometer data and these instruments are widely used to study the waves (e.g. Mathie et al., 1999 and references therein). Nevertheless, ULF waves have also strong effects on the ionospheric plasma. Coher- ent radar observations show that the periodic electric field associated to ULF waves yields a pulsed ionospheric flow (Ruohoniemi et al., 1991). Using the EISCAT incoherent radars, Lester et al. (2000) have observed periodic variations of all plasma parameters at auroral latitudes, including the electron density associated with Pc5 ULF waves. Similar observations at higher latitudes were also reported by Pitout et al. (2003), although the response of the electron density was far from clear in this case. Nevertheless, to the authors' knowledge, no connection between polar patches and ULF waves has been suggested previously.

\section{Observations}

\subsection{Interplanetary magnetic field and solar wind}

The Geotail satellite has been used to monitor the external conditions on 5 January 2003. On that day, the spacecraft was flying in the solar wind, not too far from the bow shock $\left(X_{G S E}=+18 R_{E}, Y_{G S E}=-20 R_{E}, Z_{G S E}=+3 R_{E}\right)$. Figure 1 shows magnetic and particle data from the MGF and CPI instruments, respectively, with, from top to bottom, the solar wind dynamic pressure, the proton density, the bulk plasma velocity, and the three Cartesian components of the IMF in GSE.

Over the time interval of interest, that is 10:00-14:00 UT, the proton density is about $6 \mathrm{~cm}^{-3}$ and exhibits rapid but weak amplitude variations $\left(+/-1 \mathrm{~cm}^{-3}\right)$. The solar wind speed ranges from 400 up to $480 \mathrm{~km} / \mathrm{s}$. The resulting solar wind dynamic pressure has a mean value of $2 \mathrm{nPa}$, which is quite common. To be noted, a slight increase in solar wind pressure occurs at $\sim 11: 15 \mathrm{UT}$.

The IMF, shown in the three last panels of Fig. 1, is a priori not favorable for strong and effective coupling between the solar wind and the magnetosphere. As a matter of fact, IMF $B_{z}$ is stable between 0 and $+2 \mathrm{nT}$ over our time interval of interest (11:00-12:00 UT). The $Y$-component is strongly negative around $-6 \mathrm{nT}$, giving a clock angle close to $90^{\circ}$. The IMF reaches therefore the magnetosphere almost horizontally. Interestingly enough, the $X$-component of the IMF follows nearly the same trend as the solar wind bulk velocity.

\subsection{CLUSTER}

On 5 January 2003, the CLUSTER spacecraft (Escoubet et al., 2001) were flying in the dusk sector of the dayside magnetosphere at $X_{G S E} \sim 2 R_{E}, Y_{G S E} \sim 10 R_{E}, Z_{G S E} \sim 7 R_{E}$. The resulting distance to the Earth is about $12 R_{E}$. The satellites were therefore in a good position to fly near the magnetopause. They indeed encountered the magnetopause between $\sim 11: 30$ and 14:00 UT, a time interval over which the CIS (Rème et al., 2001) and FGM (Balogh et al., 2001) instruments on board display characteristics of what looks like either multiple magnetopause crossings or multiple magnetosheath plasma injections. 

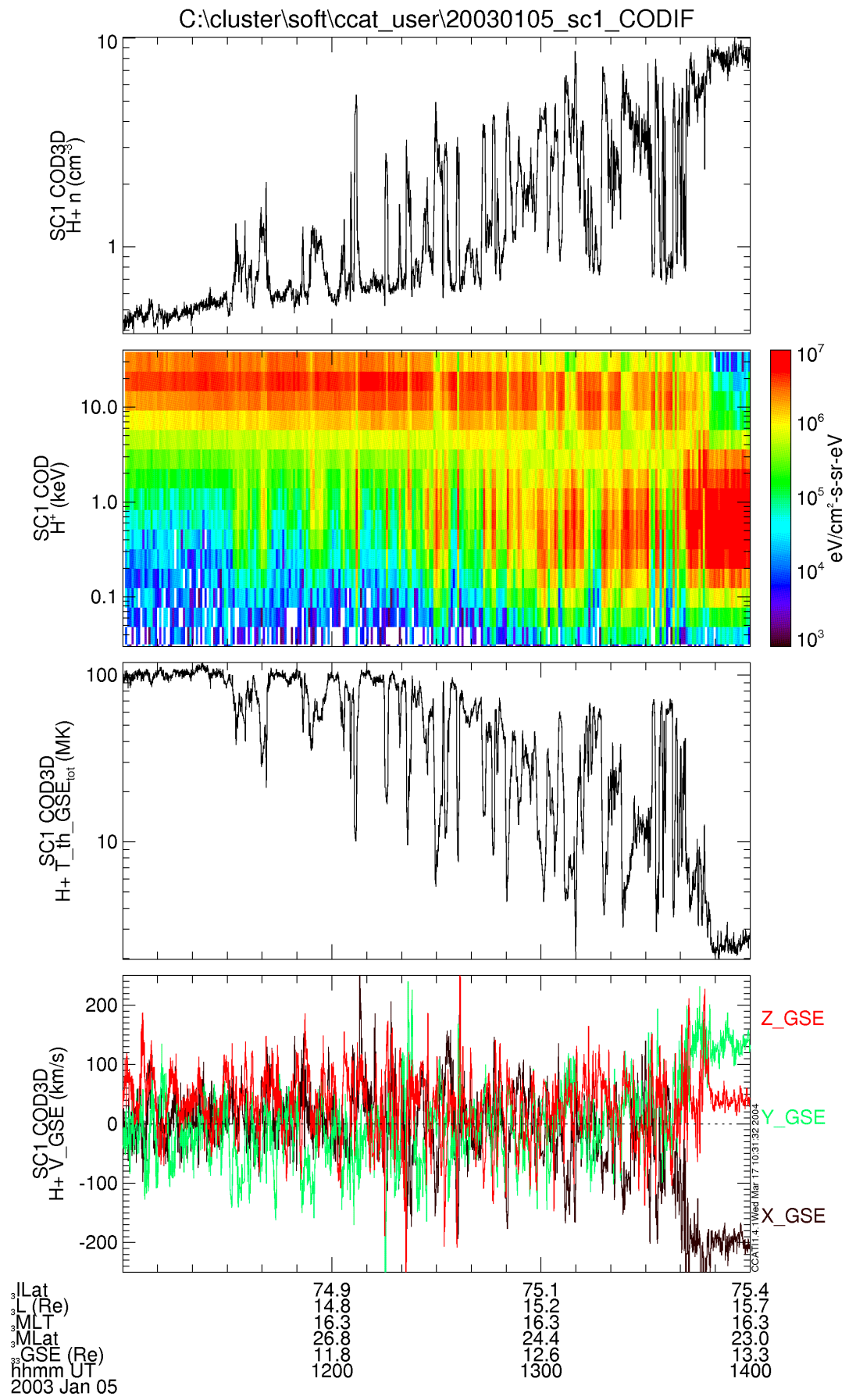

Fig. 2. CIS-CODIF data on board Cluster (S/C 1). From top to bottom are shown the proton density, a proton energy spectrogram, the proton temperature, and the three components of the proton velocity in GSE.

Figure 2 shows CIS-CODIF data for protons from S/C 1 between 11:00 and 14:00 UT. From top to bottom are displayed the density, an energy spectrogram, the total temperature, and the three GSE-components of the velocity. Three time intervals, corresponding to three different regions, can be identified.

Before 11:30 UT, only high-energy ions are recorded and the density is very low. This corresponds to trapped particles on closed magnetospheric field lines (dayside plasma sheet).
After 13:45 UT, no more high-energy ions are recorded, the ion temperature is lower than $1 \mathrm{keV}$. Besides, the density is around $10-12 \mathrm{~cm}^{-3}$, which is about twice as much as in the solar wind and the velocity is strongly anti-sunward and duskward. All this is consistent with a spacecraft being in the dusk-side magnetosheath.

More interestingly for our study, the time period between 11:30 and 13:45 UT corresponds to the transition from the magnetosphere to the magnetosheath. Regions of 


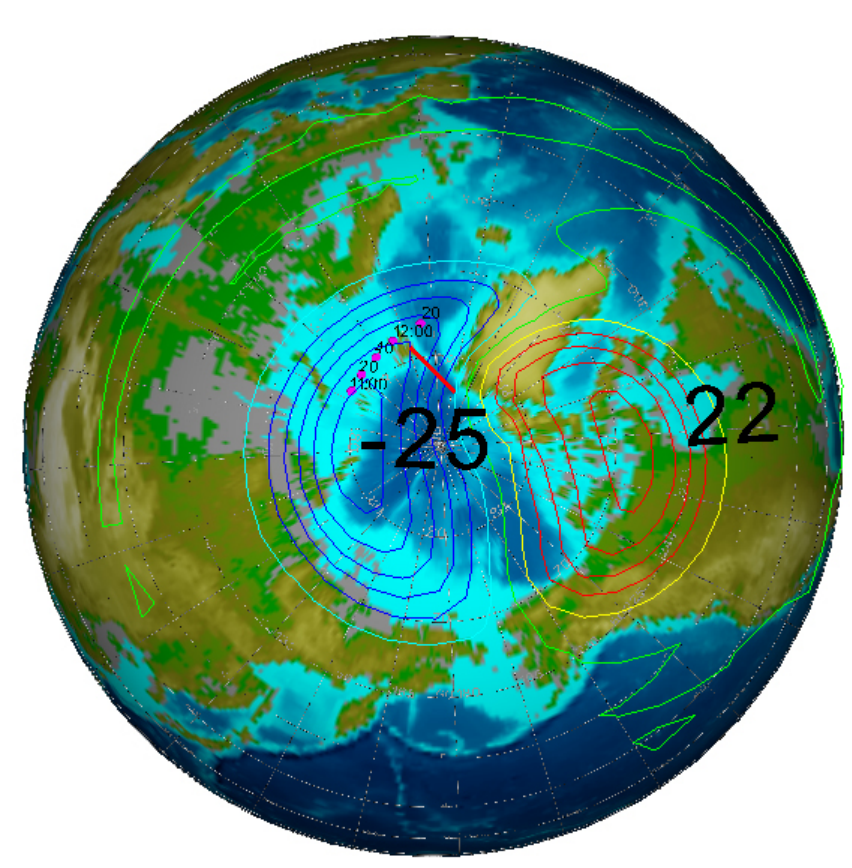

Fig. 3. Ionospheric footprint of the Cluster spacecraft. The line-ofsight of the EISCAT Svalbard Radar is in red. The colored lines are the iso-potential lines, and 22 and -25 are the electrical potentials of the morning and afternoon cells, respectively, as predicted by the Weimer-96 model.

lower-energy ions of magnetosheath origin are at times observed along with a more or less clear absence of high-energy magnetospheric ion population. We will have to analyze Cluster data in more detail, in order to find out whether those structures correspond to magnetosheath plasma injections or to magnetopause crossings. Furthermore, it has to be noticed that neither the density nor the temperature reaches magnetosheath values during those events. In addition, in the energy spectrogram, we cannot see the very low energy protons in those structures and in fact, the lower energy detected decreases as the satellites got closer and closer to the magnetosheath. This suggests that the first structures are rather boundary layer/magnetopause encounters, rather than actual magnetopause crossings.

There are obviously differences between the satellites as they are not at the same distance from the magnetopause. To understand Cluster observations, one should keep in mind that $\mathrm{S} / \mathrm{C} 4$ is the closest to the magnetopause, S/C 3 is the furthest, and $\mathrm{S} / \mathrm{C} 1$ is in an intermediate position.

\subsection{EISCAT Svalbard Radar}

As Fig. 3 shows, the footprint of the Cluster constellation passes near the ESR on 5 January 2003 between 11:00 and 13:00 UT. The ESR (Röttger et al., 1995) is the latest radar of the European Incoherent SCATter scientific organization. The facility comprises two dishes: a 32-m dish that is fully steerable in elevation and azimuth, and a 42-m dish that is fixed and pointing along the local magnetic field. On 5
January 2003, the steerable antenna was operated in the socalled "Cluster mode". It was pointing toward the magnetic pole (azimuth $-24^{\circ}$ ) and at low elevation $\left(30^{\circ}\right)$. This mode is particularly suitable to comparative Cluster/ESR studies (Lockwood and Opgenoorth, 1995).

Figure 4 displays the data recorded by the $32-\mathrm{m}$ dish between 10:00 and 14:00 UT. The four panels show, from top to bottom, the electron density, the electron temperature, the ion temperature, and the ion velocity along the line of sight as functions of magnetic latitude and universal time. The ESR system sounds reasonably well the ionosphere between 90 and $800 \mathrm{~km}$ in range along the field of view. At $30^{\circ}$ elevation, those ranges correspond to 50 and $600 \mathrm{~km}$ of altitude approximately. Since the dish was pointing at low elevation, the ion velocity measured gives a good indication of the convection velocity.

The electron density panel shows plasma structures progressing northward between 10:30 and 13:00 UT. The density within those structures reachs $5 \times 10^{11} \mathrm{~m}^{-3}$ while the background density is at least an order of magnitude less. It has to be noted, however, that those do not look well defined and structured compared to typical structures created by pulsed reconnection that would progress gently poleward. The authors admit that this is a very qualitative observational fact, but we shall see later that it has its importance.

The electron temperature panel shows regions of enhanced temperature $(\sim 2000 \mathrm{~K})$ compared to the background electron temperature $(\sim 1200 \mathrm{~K})$. This suggests that weak sporadic precipitation occurs or/and field-aligned currents flow.

The third panel also shows poleward moving regions of enhanced ion temperature (exceeding $3000 \mathrm{~K}$ ) while the background temperature is around $1500 \mathrm{~K}$.

The fourth and last panel on Fig. 4 displays the very peculiar behavior of the ionospheric plasma on that day. Between around 10:40 and 12:30 UT, the convection velocity exhibits a pulsed behavior with both positive (poleward motion) and negative (equatorward motion) values successively, ranging from $-200 \mathrm{~m} / \mathrm{s}$ to $400 \mathrm{~m} / \mathrm{s}$, typically. We remind the reader that such plasma velocities correspond to electric fields of $10 \mathrm{mV} / \mathrm{m}$ (westward) and $20 \mathrm{mV} / \mathrm{m}$ (eastward), respectively. This is clearly observed in the latitude range from 77 to $79.5^{\circ}$ MLAT. This signature is quite different than that of pulsed reconnection. Such strong equatorward flows are definitely not expected in the case of reconnection. It does, however, look like the response to ULF waves as reported, for instance, by Ruohoniemi et al. (1991). The periodic electric field associated with the wave was observed to yield pulsed flow very similar to these observed here.

The phase velocity of the density structures can be estimated by measuring their slopes in the electron density (top panel). This method leads to values between 300 and $500 \mathrm{~m} / \mathrm{s}$, which is consistent with the velocities measured (bottom panel).

We should point out that there is very little activity in the data from the ESR field-aligned antenna. This suggests that the ionosphere reacts mainly at latitudes higher than $75^{\circ}$ MLAT. 


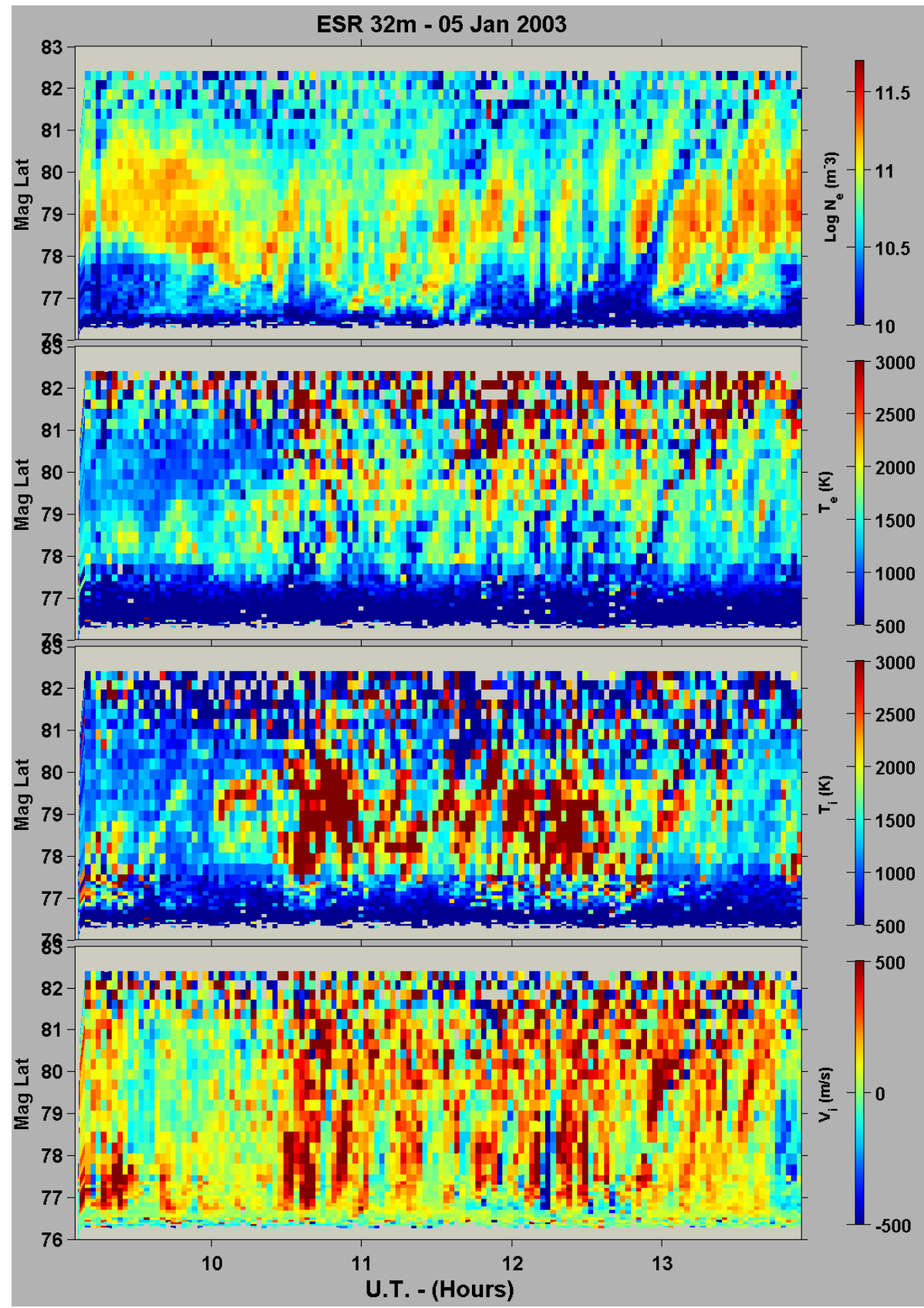

Fig. 4. Four ionospheric parameters as measured by the ESR-32m antenna as functions of magnetic latitude and universal time.

\subsection{IMAGE data}

The IMAGE magnetometer network lies across Scandinavia from Tartu, Estonia (54\%47 CGM latitude) to Ny Ålesund, Svalbard $\left(75^{\circ} 25 \mathrm{CGM}\right.$ latitude). Figures 5 and 6 display, respectively, stack plots of the $X$ - and $Y$-components of the ground magnetic field from the eight northernmost stations. Let us remind the reader that a positive deviation in the $X$-component is equivalent to an eastward current (or westward convection), whereas a positive deviation of the $Y$ component is equivalent to a equatorward current (or poleward convection), provided, of course, that the base line (deviation 0 ) is set properly.
The stations installed on the Svalbard archipelago (NAL, LYR, HOR and HOP) show some wave packets between 11:00 and 12:30 UT. They are observed both in $X$ - and $Y$-components and are seen to propagate northward in the $X$-component (phase effect). We should point out that the amplitude of those waves is very weak, a few tens of $\mathrm{nT}$ at most. Interestingly enough, there is no or very little counterpart at lower latitudes. It seems that IMAGE magnetometers only record the southern edge of the wave activity. At last, the $X$-component gives us a valuable indication on the zonal convection. Although this component is predominantly negative (eastward convection) before 12:00 UT, its value is weak. This suggests that these observations are not made 


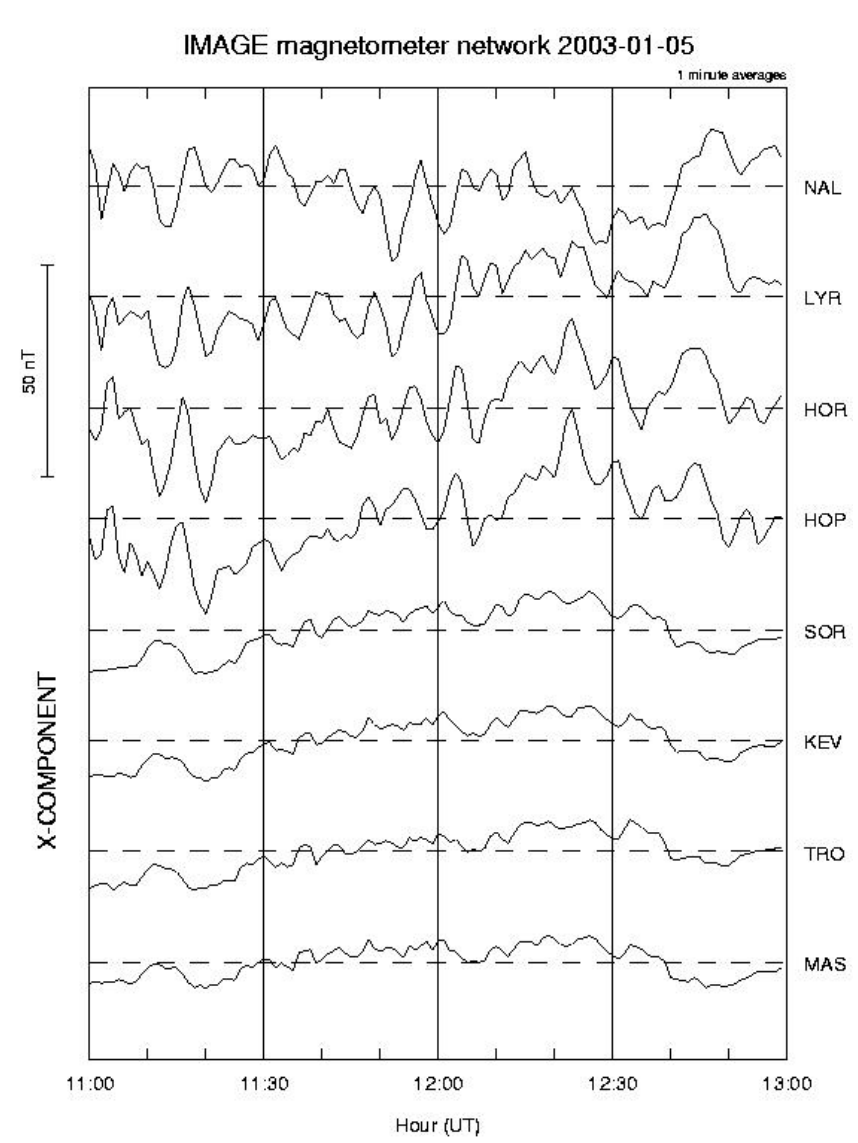

Fig. 5. $X$-component of the ground magnetic field as measured by a few selected IMAGE stations (with the northernmost station on top and the southernmost station at the bottom).

on open field lines (weak convection), therefore, not in the eastward flow channel expected for such IMF conditions and predicted by the Weiner model (Fig. 3).

\section{Data analysis and interpretation}

\subsection{Cluster data analysis}

The prevailing dawnward IMF (Fig. 1) is a priori not favorable for having reconnection in the dusk sector of the Northern Hemisphere. Indeed, reconnection is expected to occur in the morning sector of the Northern Hemisphere for negative IMF $B_{y}$ (Crooker, 1988). In order to find out whether the magnetosheath plasma sporadically observed by ClusterCIS is or is not due to reconnection, we have at our disposal a series of tests.

First of all, we can search the normal vector coordinates. It has been shown that reconnection events commonly have a characteristic signature in magnetic field data: a bipolar behavior of the component normal to the magnetopause. The minimum variance analysis technique (Sonnerup and Cahill, 1967; Sonnerup and Schieble, 1997) has been performed on magnetic field data from the FGM instrument on board Clus-

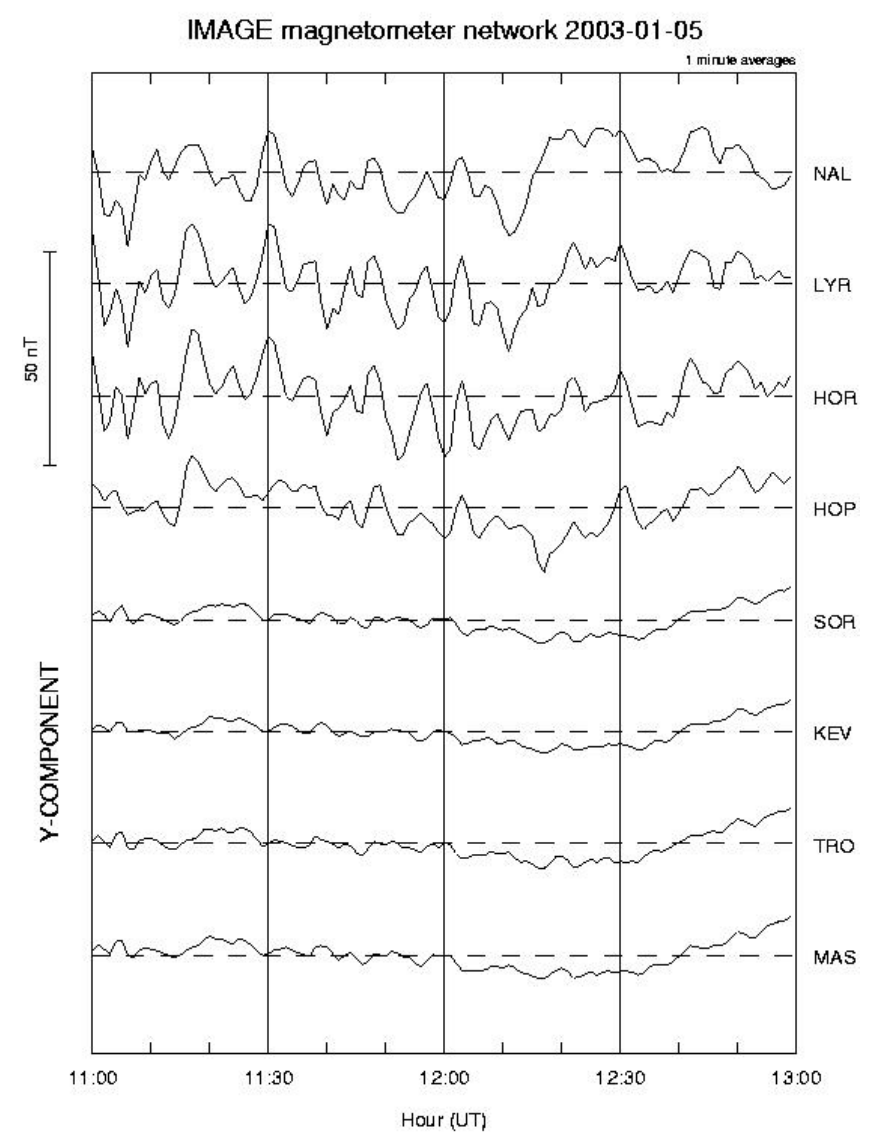

Fig. 6. $Y$-component of the ground magnetic field as measured by a few selected IMAGE stations (with the northernmost station on top and the southernmost station at the bottom).

ter, in order to calculate the vector normal to the magnetopause. The method determines that direction along which the quantity $\left\{\mathbf{B}^{(m)} \hat{\mathbf{n}}\right\}$ has minimum variance. We use $\mathrm{M}$ data points indexed by $(\mathrm{m})$. In other words, $\hat{\mathbf{n}}$ is determined by minimizing:

$\sigma^{2}=\frac{1}{M} \sum_{m=1}^{M}\left|\left(\mathbf{B}^{(m)}-\langle\mathbf{B}\rangle\right) \cdot \hat{\mathbf{n}}\right|^{2}$.

Once $\hat{\mathbf{n}}$ is found, we can project the magnetic field on the boundary normal coordinate system $(\mathrm{L}, \mathrm{M}, \mathrm{N})$. The result is shown in Fig. 7, which shows, from top to bottom, the $X$-, $Y$-, and $Z$-components of the magnetic field in the GSE coordinate system, followed by the L-, M- and N-components in the boundary normal coordinate system. No bipolar signatures are visible in the component normal to the magnetopause ( $N$-component). A doubt remains however. As a matter of fact, Owens et al. (2003) have reported clear FTEs that have no bipolar signature in the magnetic field data.

The next step is to find out whether a deHoffmann-Teller (dHT) frame exists. In such a frame, the electric field $\mathbf{E}$ ' vanishes:

$\mathbf{E}^{\prime}=\mathbf{E}+\mathbf{V}_{H T} \times \mathbf{B}=0$. 

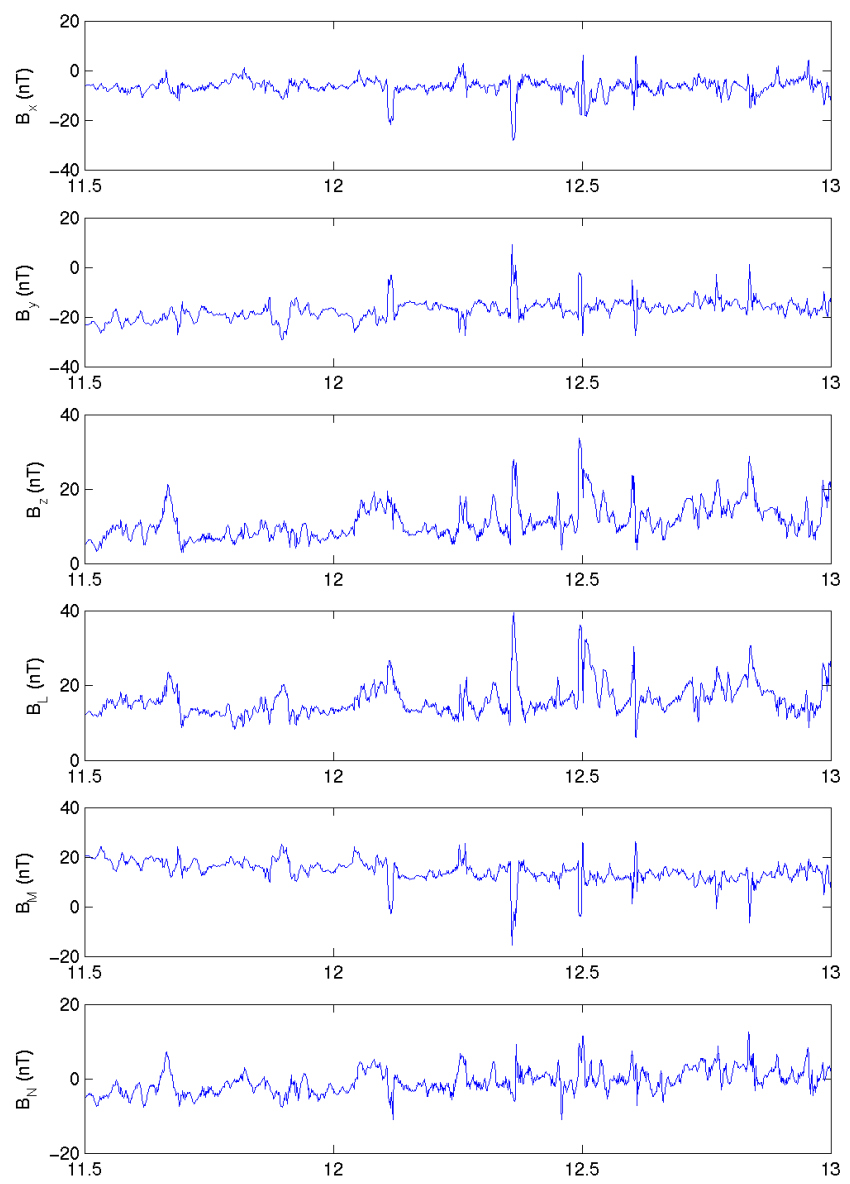

Fig. 7. Magnetic field as measured by Cluster-FGM on board S/C 4 with, from top to bottom, the three GSE components and the three LMN components.

The existence of such a frame would imply that the magnetic field structure is stationary in that frame. The velocity of the $\mathrm{dHT}$ frame can be determined from experimental data by the method of minimization of residual electric field (Khrabrov and Sonnerup, 1997). In practice, one has to find the velocity V that minimizes the quantity:

$D(\mathbf{V})=\frac{1}{M} \sum_{m=1}^{M}\left|\mathbf{E}^{\prime(m)}\right|^{2}=\frac{1}{M} \sum_{m=1}^{M}\left|\left(\mathbf{v}^{(m)}-\mathbf{V}\right) \times \mathbf{B}^{(m)}\right|$.

We have performed this technique on several structures corresponding to magnetosheath plasma observations. We have plotted the two electric fields $\mathbf{E}^{(m)}=\mathbf{v}^{(m)} \times \mathbf{B}^{(m)}$ and $\mathbf{E}_{H T}^{(m)}=\mathbf{V}_{H T} \times \mathbf{B}^{(m)}$ against each other (not shown). Despite the poor correlation coefficient due to a substantial scattering of the data points, it seems that a slope close to 1 is found in each case. This would suggest that a dHT frame does exist for each one of the structures. Nonetheless, as mentioned, the weak correlation coefficient casts doubt on the validity of this test and consequently, on the actual existence of a dHT frame.

The last step is the verification of the Walén test. If the structures are of reconnection origin, then they should be
Table 1. Angles between normal to boundary at exit and entry for the selected 5 events.

\begin{tabular}{ccc}
\hline Event \# & $\begin{array}{c}\text { Exit and reentry timing } \\
(\text { hh:mm:ss) }\end{array}$ & $\begin{array}{c}\text { Angle between normal } \\
\text { vectors }\left(^{\circ}\right)\end{array}$ \\
\hline 1 & $11: 39: 33-11: 40: 08$ & 14.9 \\
\hline 2 & $11: 54: 52-11: 55: 53(?)$ & 41.5 \\
\hline 3 & $12: 06: 22-12: 07: 12$ & 6.5 \\
\hline 4 & $12: 21: 20-12: 22: 12$ & 17.6 \\
\hline 5 & $12: 29: 19-12: 31: 41(?)$ & 62 \\
\hline
\end{tabular}

moving at Alfvén speed in the dHT frame (Khrabrov and Sonnerup, 1997):

$\mathbf{v}^{(m)}-\mathbf{V}_{H T}= \pm \mathbf{V}_{A}^{(m)}= \pm \frac{\mathbf{B}^{(m)}}{\sqrt{\mu_{0} \rho^{(m)}}}$

For all events, the Walén scatter plots of the plasma velocity in the dHT frame $\left(\mathbf{v}^{(m)}-\mathbf{V}_{H T}\right)$ versus the corresponding components of the Alfvén velocity $\mathbf{V}_{A}^{(m)}$ reveal slopes of about 0.2 . The plasma in the dHT frame clearly does not move at Alfvén speed.

A first conclusion to this data analysis is that, since the plasma does not flow at Alfvén speed in the dHT frame, we are not in the presence of rotational discontinuities. Those structures do not therefore originate from reconnection. The alternative possibility is that the Cluster spacecraft encountered the magnetopause at several occasions due to a global motion of the layer or/and a distortion of the layer's surface by some surface waves.

In order to determine the magnetopause motion, we have calculated the angle between the normal vectors to the boundary for selected crossings, that is, for the exit and the corresponding reentry. The method used was the MVA, described above. The idea is the following. If the angle between the two normal vectors is small, ideally zero (in fact $180^{\circ}$ ), it means that the magnetopause acts as a planar surface passing back and forth over the spacecraft. If the normal vectors are different, then a surface wave may be the cause of the crossings (Owen et al., 2003). In our case, we have found very small angles (see Table 1), except for events 2 and 5 for which the boundaries are not clearly defined. These small angles do suggest that the magnetopause has an in-out breathing motion rather than a surface wave traveling along its flanks. Besides, a surface wave would imply typical frequencies in the boundary crossings. No such frequencies are observed in this case.

\subsection{ESR data analysis}

Radar data do not need so much analysis besides the analysis done by the GUISDAP analysis package (Lehtinen and Huuskonen, 1996) to extract the plasma parameters from the 


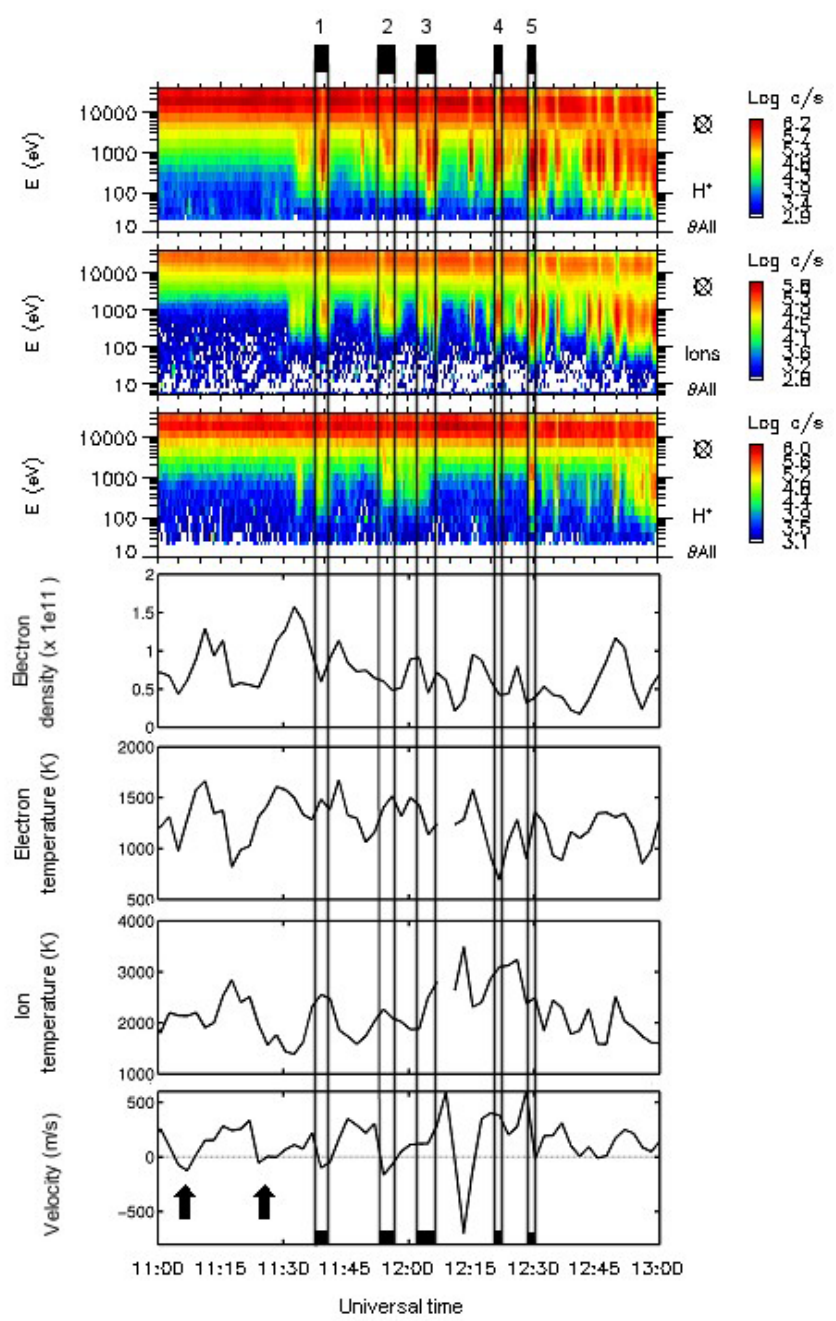

Fig. 8. Space-ground correlation. The three upper panels show CIS ion spectrograms from S/C4 (CODIF), S/C1 (HIA), and S/C3 (CODIF). The four following panels show time series of ionospheric plasma parameters, as measured by the ESR-32m, averaged between 170 and $260 \mathrm{~km}$.

raw data. However, we have noticed significant differences between data taken at neighboring ranges (or latitudes), very likely due to some noise. In the forthcoming discussion, we have thus decided to average the data between 78 and $79^{\circ}$ MLAT, in order to avoid or at least to minimize those deviations. In terms of altitude, this means that we average between about 170 and $260 \mathrm{~km}$ (F-region).

\subsection{Space-ground correlations}

Let us look closely at the correlations between the observations made by Cluster and the ESR. When Cluster is relatively more inside the magnetosphere, it is easy to imagine that the incursions it does in the boundary layer/magnetopause or in the magnetosheath correspond to large amplitude displacements of the magnetopause (whatever the cause). We can also reasonably foresee that those large amplitude displacements will have dominant effects on the ionosphere. By using the multi-point capability of Cluster, we have therefore two complementary ways of tracking large amplitude displacements. First, if S/C 1 and S/C 4, which are closer to the magnetopause, fully cross the magnetopause, then there should be a cutoff in the high-energy ions as measured by CIS. Second, being more inside the magnetosphere, S/C 3 should be able to detect magnetosheath ions only for the larger magnetopause displacements. We have used jointly these two criteria to identify the magnetopause crossings where we expect to have a measurable effect on the ionosphere plasma and fields.

Figure 8 shows, from top to bottom, ion spectrograms from S/C 4, S/C 1, and S/C 3, as well as time series of the four averaged plasma parameters as measured by the ESR (see Sect. 3.2). We have marked and numbered 5 events between 11:00 and 12:30 UT, as follows: 1, 2, 3, 4, 5 at $\sim 11: 40$, $\sim 11: 55,12: 05,12: 20$ and 12:30 UT respectively. It appears clearly that each inward motion of the magnetopause triggers sunward ionospheric flows or at least decreases the convection velocity, allowing plus or minus a couple of minutes for propagation and for errors due to the post-integration time (128 s) of the ESR data.

The two first events of sunward ionospheric flows recorded by the ESR at $\sim 11: 05$ and 11:20 UT (marked by black arrows in Fig. 8) are very likely due to the magnetopause motion as well. Cluster was probably not close enough to the magnetopause to encounter it and therefore unable to monitor its displacement. As a matter of fact, by looking closely at the solar wind data (Fig. 1), it would be more exact to state that it was the magnetopause that was not close enough to the satellites. A non-moving magnetopause should have been encountered gradually by each satellite depending on their respective distance to the layer. On the contrary, the satellites have their first encounter with the magnetopause shortly after 11:30 UT suggesting that the magnetopause actually moves over them. Figure 1 does reveal that the solar wind dynamic pressure increased from 2 to $3 \mathrm{nP}$ at around 11:15 UT. It makes sense to think that this yielded a small compression of the magnetopause.

We also find wave-like patterns in the ground magnetograms, suggesting that the information travels by means of ULF waves.

\section{Discussion}

To summarize, we have observed ionospheric density structures near the footprint of the Cluster spacecraft, which observed non-tangential discontinuity at the magnetopause (no injections).

The magnetosheath plasma that Cluster observes does not, as we showed, correspond to injections. The only alternative is that the magnetopause moved over the satellite in one way or another (surface waves, magnetopause motion, or both). In any event, the magnetic signature on the ground is a ULF wave signature. 

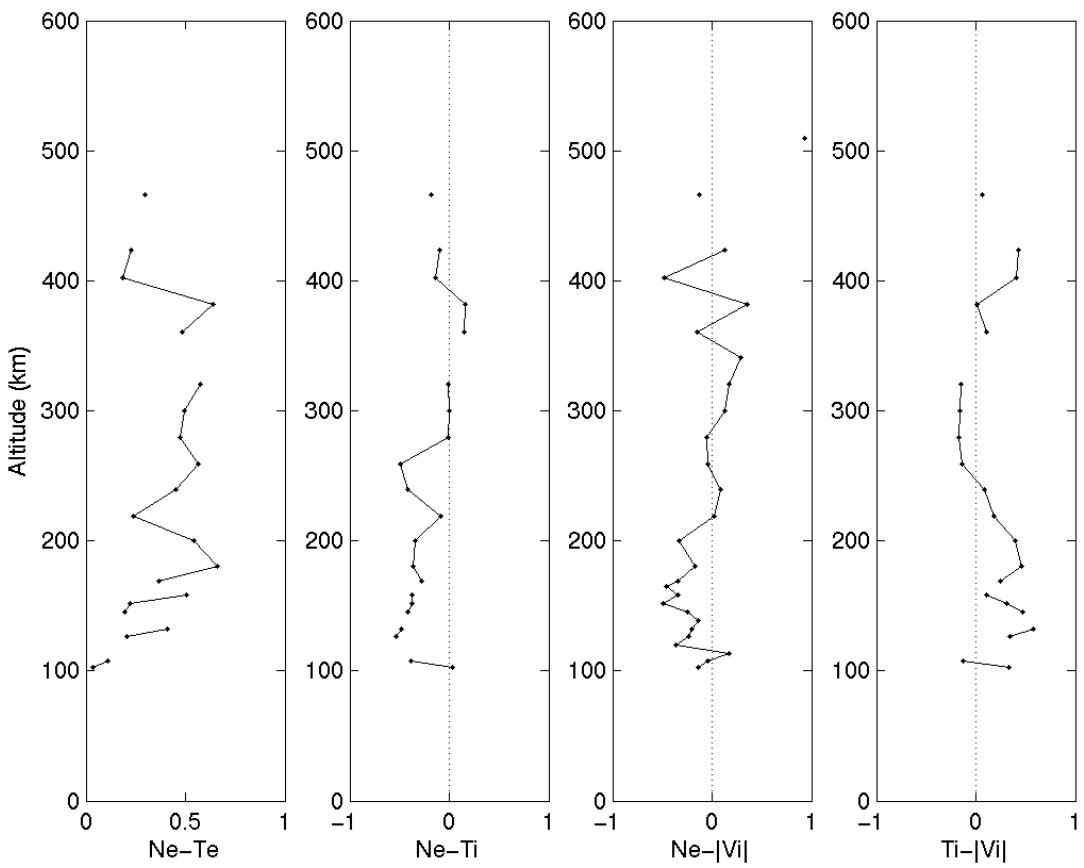

Fig. 9. Correlation coefficients between paired ionospheric parameters versus altitude.

Figure 8 shows, in its lower part, the time series of the ionospheric plasma parameters as recorded by the ESR around $78^{\circ}$ MLAT. We have numbered five events corresponding to reversed (sunward) convection and identified two more. These five events are also clearly identified in Cluster-CIS data from all 3 satellites.

This surprising correlation suggests that the pulsed ionospheric flow is a response to the magnetopause motion. This would suggest, in turn, that the density structures are produced locally by particle precipitation (electron temperature high) and/or by electron density depletion due to fast flow. On the other hand, it has to be noted that the electron temperature is much lower than the ion temperature. This suggests that electron precipitation is very weak and that the chemistry is ruled by the ions temperature and consequently, by the convection.

However, we would like to discuss a possibility that has crossed the authors' mind. The plasma patches could have been created elsewhere and they would have drifted towards the field of view of the radar. We already mentioned that the IMF is not quite favorable to effective coupling between the solar wind and the magnetosphere. In addition, if reconnection takes place under strong IMF $B_{y}$ (Crooker, 1988), then it should be in the morning sector according to the IMF orientation. Could the plasma structures observed have been produced by reconnection in the morning sector? In principle, yes. Strong zonal flow channels under northward and $B_{y}$-dominated IMF have been already observed (e.g. Nilsson et al., 1997). As matter of fact, in our case, iso-contours of electric potential in Fig. 3 clearly show that the cusp region is in the afternoon sector and that the convection is eastward. What the waves would have done then would have been to alter, so to say, the plasma structures already existing. In this case, though, the plasma structures should be clear and unaltered in the very high-latitude ionosphere (above $80^{\circ}$ MLAT).

In order to attempt to solve this problem, we have compared the correlation between four pairs of ionospheric parameters for each altitude/latitude. Figure 9 shows correlation coefficients between paired ionospheric parameters as measured by the ESR: $\mathrm{N}_{e} \mathrm{P}-\mathrm{T}_{e}, \mathrm{~N}_{e}-\mathrm{T}_{i}, \mathrm{~N}_{e}-\left|\mathrm{V}_{i}\right|$, and $\mathrm{T}_{i}-\left|\mathrm{V}_{i}\right|$ (respectively, from left to right) as a function of altitude.

The correlation between electron density and temperature is positive and high when precipitation occurs: precipitating electrons warm up the ionosphere and contribute to increase the density. The first panel (from left) in Fig. 9 shows that the correlation coefficient between $\mathrm{N}_{e}$ and $\mathrm{T}_{e}$ fluctuates around 0.5 , which is not very high. This indicates that the two parameters are linked to each other but that the precipitation is not the only process that affects the electron density.

The electron density and the ion temperature are generally anti-correlated. A high ion temperature enhances frictional heating that, in turn, modifies the chemistry in the ionosphere and tends to deplete the electron population (Schunk et al., 1975). This is well observed in the second panel of Fig. 9, up to $\sim 270 \mathrm{~km}$ of altitude. This is not an altitude affect, as ion temperature enhancements (due to strong convection) affect the whole altitude range. This must be a latitude effect. Indeed, we saw earlier that the wavy ionospheric convection pattern was observed up to $79.5^{\circ}$ MLAT, which precisely corresponds to an altitude of $260 \mathrm{~km}$. Therefore, as already suspected, $\mathrm{T}_{i}$ comes into play locally in the formation of density structures. 
When it comes to $\mathrm{V}_{i}$, it is much more difficult to compare it with the other parameters, as $\mathrm{V}_{i}$, as measured by the ESR, is only one component of the convection velocity. Besides, it is not straightforward to link $\mathrm{V}_{i}$ and $\mathrm{T}_{i}$, for instance, as $\mathrm{T}_{i}$ is not sensitive to the velocity itself, nor to its amplitude, but to the differential velocity between ions and neutrals. Since we have no measurement of the neutral wind, it would be illusive to want to draw any conclusion. However, we have tried to compare $\left|\mathrm{V}_{i}\right|$ with $\mathrm{N}_{e}$ and $\mathrm{T}_{i}$ (third and fourth panels from left in Fig. 9). The correlation between $\mathrm{N}_{e}$ and $\left|\mathrm{V}_{i}\right|$ appears to be weakly negative up to $200 \mathrm{~km}$. This suggests that convection does affect the electron density, as already evoked, by warming up the ion temperature and depleting the electron population (negative correlation means that a high velocity induces a low density). The last panel, which shows that the ion velocity and temperature are positively correlated up to about $200 \mathrm{~km}$ confirms this.

One event remains puzzling. The sunward flow event around 12:15 UT seen in ESR data has a counterpart in CIS data only from S/C4 and 1 . Since almost nothing is detected on S/C 3 (in fact, there is a faint and brief detection of magnetosheath-like plasma by HIA), more inside the magnetosphere, this suggests that the magnetopause motion responsible for this event has a relatively small amplitude. Yet, it is the strongest sunward flow velocity measured over the whole time interval. There are several explanations for this event. The first is a corrupted ESR data point. More optimistically, it may also be an inner ionospheric process that would not have anything to do with the magnetopause. Alternatively, could a fast but small-amplitude inward motion of the magnetopause give birth to such a ground signature? This would mean that the ionospheric flow is sensitive to the speed of the magnetopause motion, rather than its amplitude. This should be investigated in the future.

At last, we would like to emphasize that the latitude footprint of Cluster given by the Tsyganenko model T96 (OVT plot, Fig. 3) must be underestimated. Indeed, the good correlation between ESR and Cluster means that they observe the same phenomenon, which does not seem to have any effect at the latitudes given by T96 as the footprint of Cluster. The actual footprint of the spacecraft must then be at higher latitude. This is confirmed by the fact that the IMAGE magnetometers record small amplitude waves at ESR latitude and that the field-aligned antenna (data not shown) show very little activity as well.

\section{Conclusion}

Polar patches in the polar ionosphere have been observed for many decades and several processes were proposed to explain their formation. In this paper, we have reported a peculiar case of observations of ionospheric density structures in the polar cap. The analysis of both ESR and Cluster data suggest that another process may exist, namely the formation of density structures by pulsed ionospheric flows associated to ULF waves. In our case, it is unfortunate that the magne- topause activity is monitored by Cluster only from 11:30 UT onward, because the activity on the ground started much earlier. However, the time interval we have studied was very interesting and allowed us to draw a few conclusions. The electron density recorded by the ESR exhibits structures of enhanced density while the flow pattern is very similar to that observed for ULF wave activity. The patches appear to be, if not locally produced, at least locally reshaped or altered by the varying convection velocity. Comparisons of Cluster and ground data showed that the ionospheric activity is tightly related to the magnetopause motion. Cluster data analysis allowed us to determine that the movement of the magnetopause is an in-out breathing rather than displacements related to magnetic reconnection or surface waves traveling along its flank. The identified sunward ionospheric flow events associated with plasma depletion regions correspond to inward displacements of the magnetopause.

Acknowledgements. The authors are grateful to the director and staff of the EISCAT Scientific Association for providing the radar facilities and assistance with making the observations. EISCAT is an international association, supported the research councils of Finland, France, Germany, Japan, Norway, Sweden and the United Kingdom. We are also grateful to the Cluster CIS and FGM PIs: H. Rème and A. Balogh respectively. Geotail data were retrieved from CDAWeb. We thank the institutes, which maintain the IMAGE magnetometers array. The IMAGE magnetometer data are collected as a Finnish-German-Norwegian-Polish-Russian-Swedish project. We thank the OVT team for their valuable visualization tool. ESR data were plotted with routines developed by Denis Alcaydé. We have used CCATi and CL software (developed by the CIS teams) to plot CIS data. We would like to thank M. Fränz and E. Penou for their assistance and help in using these analysis tools.

Topical Editor T. Pulkkinen thanks I. Dandouras and another referee for their help in evaluating this paper.

\section{References}

Balogh, A., Carr, C. M., Acuña, M. H., Dunlop, M. W., Beek, T. J., Brown, P., Fornacon, K.-H., Georgescu, E., Glassmeier, K.H., Harris, J., Musmann, G., Oddy, T., and Schwingenschuh, K.: The Cluster Magnetic Field Investigation: overview of in-flight performance and initial results, Ann. Geophys., 19, 1207-1217, 2001.

Crooker, N. U.: Mapping the merging potential from the magnetopause to the ionosphere through the dayside cusp, J. Geophys. Res., 93, 7338-7344, 1988.

Escoubet, C. P., Fehringer, M., Goldstein, M.: The Cluster mission, Ann. Geophys., 19, 1197, 2001.

Khrabrov, A. V. and Sonnerup, B. U.Ö.: DeHoffman-Teller Analysis, Methods for Multi-Spacecraft Data - ISSI scientific report, SR-001, 221, 1997

Lehtinen, M. S. and Huuskonen, A.: General incoherent scatter analysis and GUISDAP, J. Atmos. Terr. Phys., 58, 435-452, 1996.

Lester, M., Davis, J. A., and Yeoman, T. K.: The ionospheric response during an interval of Pc5 ULF wave activity, Ann. Geophys., 18, 257-261, 2000. 
Lockwood, M. and Carlsson Jr., H. C.: Production of polar cap electron density patches by transient magnetopause reconnection, Geophys. Res. Lett., 19, 1731-1734, 1992.

Lockwood, M. and Opgenoorth, H. J.: Opportunities for magnetospheric research using EISCAT/ESR and CLUSTER, J. Geomag. Geoelectr., 47, 699-721, 1995.

Mathie, R. A., Mann, I. R., Menk, F. W., Orr, D.: Pc5 ULF pulsations associated with waveguide modes observed with the IMAGE magnetometer array, J. Geophys. Res, 104, 7025, 1999.

Nilsson, H., Yamauchi, M., Mukai, T., Yamamoto, T., and Moretto, T.: Observations of an enhanced convection flow channel for northward turning IMF, Geophys. Res. Lett., 24, 3137-3140, 1997.

Owen, C. J., Taylor, M. G. G. T., Krauklis, I. C., Fazakerley, A. N., Dunlop, M. W., and Bosqued, J.-M.: Cluster observations of surface waves on the dawn flank magnetopause, Ann. Geophys., 22, 971-983, 2004.

Pitout, F., Eglitis, P., Blelly, P.-L.: High-latitude dayside ionosphere response to Pc5 field line resonance, Ann. Geophys., 21, 15091520, 2003.

Pitout, F. and Blelly, P.-L.: Electron density in the cusp ionosphere: increase or depletion?, Geophys. Res. Lett., 30, 17261729, 2003.

Rème, H., Aoustin, C., Bosqued, J. M., Dandouras, I., Lavraud, B., Sauvaud, J. A., Barthe, A., Bouyssou, J., Camus, Th., CoeurJoly, O., Cros, A., Cuvilo, J., Ducay, F., Garbarowitz, Y., Medale, J. L., Penou, E., Perrier, H., Romefort, D., Rouzaud, J., Vallat, C., Alcaydé, D., Jacquey, C., Mazelle, C., d'Uston, C., Möbius, E., Kistler, L. M., Crocker, K., Granoff, M., Mouikis, C., Popecki, M., Vosbury, M., Klecker, B., Hovestadt, D., Kucharek, H., Kuenneth, E., Paschmann, G., Scholer, M., Sckopke, N., Seidenschwang, E., Carlson, C. W., Curtis, D. W., Ingraham, C., Lin, R. P., McFadden, J. P., Parks, G. K., Phan, T., Formisano, V., Amata, E., Bavassano-Cattaneo, M. B., Baldetti, P., Bruno, R., Chionchio, G., Di Lellis, A., Marcucci, M. F., Pallocchia, G., Korth, A., Daly, P. W., Graeve, B., Rosenbauer, H., Vasyliunas, V., McCarthy, M., Wilber, M., Eliasson, L., Lundin, R., Olsen, S., Shelley, E. G., Fuselier, S., Ghielmetti, A. G., Lennartsson, W., Escoubet, C. P., Balsiger, H., Friedel, R., Cao, J-B., Kovrazhkin, R. A., Papamastorakis, I., Pellat, R., Scudder, J., and Sonnerup, B.: First multispacecraft ion measurements in and near the Earth's magnetosphere with the identical Cluster ion spectrometry (CIS) experiment, Ann. Geophys., 19, 1303, 2001.
Rodger, A. S., Pinnock, M., Dudeney, J. R., Baker, K. B., and Greenwald, R. A.: A new mechanism for polar patch formation, J. Geophys. Res., 99, 6425-6436, 1994.

Röttger, J., Wannberg,U. G., and van Eyken, A. P.: The EISCAT Scientific Association and the EISCAT Svalbard Radar Project, J. Geomag. Geoelectr., 47, 669-679, 1995.

Ruohoniemi, J. M., Greenwald, R. A., Baker, K. B., and Samson, J. C.: HF radar observations of Pc5 Field Line Resonances in the midnight/early morning MLT sector, J. Geophys. Res., 96, 15 697-15 710, 1991.

Schunk, R. W., Raitt, W. J., and Banks, P. M.: Effect of the electric fields on the daytime high-latitude E- and F-region, J. Geophys. Res., 80, 3121, 1975.

Sonnerup, B. U. Ö., and Cahill Jr., L. J.: Magnetopause structure and attitude from Explorer 12 observations, J. Geophys. Res., $72,171,1967$.

Sonnerup, B. U. Ö. and Scheible, M.: Minimum and maximum variance analysis, Analysis Methods for Multi-Spacecraft DataISSI scientific report, SR-001, 185, 1997.

Valladares, C. E., Alcaydé, D., Rodriguez, J. V., Ruohoniemi, J. M., and van Eyken, A. P.: Observations of plasma density structures in association with the passage of traveling convection vortices and the occurrence of large plasma jest, Ann. Geophys., 17, 1020-1039, 1999.

Weimer, D. R.: A flexible, IMF-dependent model of high-latitude electric potentials having "space weather" applications, Geophys. Res. Lett., 23, 2549, 1996.

Whitteker, J. H.: The transient response of the topside ionosphere to precipitation, Planet. Space. Sci., 25, 773, 1977. 